\title{
Antibacterial and cytotoxic activities of methanolic extracts of leaf and fruit parts of the plant Averrhoa bilimbi (Oxalidaceae)
}

\author{
Sreedam Chandra Das ${ }^{{ }^{1}}$, Shapna Sultana ${ }^{1}$, Sumon Roy ${ }^{1}$, Sheikh Sayeed Hasan ${ }^{2}$ \\ ${ }^{1}$ Department of Pharmacy, Southeast University, Dhaka, Bangladesh \\ ${ }^{2}$ Department of Pharmaceutical Technology, University of Dhaka, Dhaka, Bangladesh \\ *Corresponding Author - E mail: sreedam@hotmail.com
}

\begin{abstract}
This study was conducted to evaluate the antibacterial and cytotoxic activities of extracts from leaf and fruit parts of the plant Averrhoa bilimbi (Oxalidaceae). Methanol was used as solvent and antibacterial effect was measured using disc diffusion test. The susceptibility of the microorganisms to the extracts of this plant was compared with standard antibiotic kanamycin. Fruit extract exhibited more potent antimicrobial activity against a wide variety of Gram-positive and Gram-negative bacteria compared to leaf extract. The antimicrobial activity was highest for the fruit extract against the Gram-negative Salmonella paratyphi $(23.0 \pm 0.50 \mathrm{~mm})$ and the Grampositive Bacillus megaterium $(19.0 \pm 0.40 \mathrm{~mm})$ bacteria, somewhat weaker against the Staphylococcus aureus, Bacillus subtilis, while with the leaf extract poor activity was observed against all 12 bacteria. Minimum inhibitory concentration (MIC) values were determined and it was found that the fruit extract was more potent against Salmonella paratyphi, Salmonella typhi, Shigella dysenteriae and Vibro parahemolyticus. The cytotoxic activity of fruit extract was found highly potent $(12.96 \mu \mathrm{g} / \mathrm{ml})$ where as the leaf also showed significant activity $(92.51 \mu \mathrm{g} / \mathrm{ml})$.
\end{abstract}

Keywords: Averrhoa bilimbi, Antibacterial activity, Methanolic extracts, Minimum Inhibitory Concentration, Zone of inhibition, Disc diffusion method, Cytotoxic activity, Artemia salina.

\section{INTRODUCTION}

Medicinal plants possess various medicinal properties; have been serving as the major sources of therapeutic agents for maintenance of human health. Antimicrobial research is geared toward the discovery and development of novel chemical structures such as therapeutic antimicrobial agents. The continuing problem of development of resistance to existing antibacterial agents and the dearth of good antifungal agents motivates this effort toward innovation (L. Silver et al., 1990). The brine shrimp cytotoxicity assay was considered as a convenient probe for preliminary assessment of toxicity, detection of fungal toxins, heavy metals, pesticides and cytotoxicity testing of dental materials (Meyer et al, 1982). It can also be extrapolated for cell-line toxicity and antitumor activity (Selvin et al., 2004).

Besides small molecules from medicinal chemistry, natural products are still major sources of innovative therapeutic agents for various conditions, including infectious diseases (Clardy et al., 2004). Current research on natural molecules and products primarily focuses on plants since they can be sourced more easily and selected on the basis of their ethno-medicinal use (Verpoorte et al., 2005). The antimicrobial compounds produced by plants are active against plant and human pathogenic microorganisms (Mitscher et al., 1987). In the continuation of this strategy of new drug discovery, we have studied only the leaf and fruit of the plant Averrhoa bilimbi for their antibacterial activity.

Averrhoa bilimbi belongs to the family Oxalidaceae. This is essentially a tropical tree, less resistant to cold than the carambola, growing best in rich and well-drained soil (but also stands limestone and sand). The A. bilimbi tree is longlived and reaches 5-10 $\mathrm{m}$ in height. Bilimbi leaf, 3$6 \mathrm{~cm}$ long, is alternate, imparipinnate and cluster at branch extremities. In the Philippines, the leaf serves as a paste on itches, swelling, rheumatism, mumps or skin eruptions. Elsewhere, they are used for bites of poisonous creatures. A leaf infusion is efficient against or as an after-birth tonic, while the flower infusion is used for thrush, cold, and cough. Malaysians use fermented or fresh bilimbi leaf to cure venereal diseases (Orwa et al., 2009). 
Previous phytochemical investigations showed that chloroform extracts of $A$. bilimbi's leaf and fruit have antibacterial activity against the Grampositive S. aureus, S. epidermis, B. cereus, $K$. rhizophila, C. diphteriae and Gram-negative $S$. typhi, C. fuendii, A. hydrophila and $P$. vulgaris (Jais et al., 2009). The present study was aimed to evaluate the potentiality of methanolic extracts of fruit and leaf parts of the plant Averrhoa bilimbi against some Gram-positive, Gram-negative strains of bacteria and also to evaluate the cytotoxic activity.

Plant material: Fruit and leaf of Averrhoa bilimbi were collected in February 2009 from Uttara, Dhaka, Bangladesh and were authenticated at Bangladesh National Herberium, where a voucher specimen has been deposited.

Extraction and isolation: The air-dried leaf $(1 \mathrm{~kg})$ and fruits $(600 \mathrm{~g})$ were finely pulverized and extracted by percolation with methanol for one month at room temperature. The extracts were filtered and concentrated under vacuum to obtain crude extracts of leaf $(40 \mathrm{gm})$ and fruit $(10 \mathrm{~g})$.

\section{MATERIALS AND METHODS}

Antimicrobial activity- Disc diffusion method: Antibacterial activity was tested against Bacillus megaterium, Bacillus subtilis, Staphylococcus aureus, Sarcina lutea, Escherichia coli, Pseudomonas aeruginosa, Salmonella paratyphi, Salmonella typhi, Shigella boydii, Shigella dysenteriae, Vibrio mimicus and Vibrio parahemolyticus. These bacterial strains were isolated from clinical samples and obtained as pure cultures from the Institute of Nutrition and Food Science (INFS), University of Dhaka, Bangladesh.

The leaf and fruit crude extracts were tested in vitro for antibacterial activity by the standard disc diffusion method (Bauer et al., 1966; Rahman et al., 2008) against the micro-organisms. Mother solution of sample was prepared by dissolving 4.8 $\mathrm{mg}$ of sample in $200 \mu \mathrm{l}$ of methanol. The solution was sonicated for 5 minutes for proper dissolution. Dried and sterilized filter paper discs $(6 \mathrm{~mm}$ diameter) were then impregnated with known amounts of the test substances using micropipette and the residual solvents were completely evaporated. Discs containing the test materials were placed on to nutrient agar medium uniformly seeded with the test micro-organisms. Standard disc of kanamycin (30 $\mu \mathrm{g} / \mathrm{disc})$ and blank disc (impregnated with solvents followed by evaporation) were used as positive and negative control, respectively. These plates were then kept at low temperature $\left(4^{\circ} \mathrm{C}\right)$ for 24 hours to allow maximum diffusion of the test materials and kanamycin. The plates were then incubated at $37^{\circ} \mathrm{C}$ for 24 hours to allow maximum growth of the organisms. The test material having antibacterial activity inhibited the growth of the microorganisms and a clear, distinct zone of inhibition was visualized surrounding the discs. The antibacterial activity of the test agents was determined by measuring the diameter of zone of inhibition expressed in millimeter $(\mathrm{mm})$. The experiment was carried out in triplicate and the mean value was taken.

Minimum inhibitory concentration (MIC) determination: The minimum inhibitory concentration of the fruit extract was determined against Staphylococcus aureus, Sarcina lutea, Vibrio parahemolyticus, Salmonella typhi, Shigella boydii, Shigella dysenteriae. The test was carried out by serial dilution technique (Reiner et al., 1982). Nutrient agar and broth were used as bacteriological media. Dilution series were set up with $2,4,8,16,32,64,128,256,500 \mu \mathrm{g} / \mathrm{ml}$ of nutrient broth medium. The test was continued out in triplicates. The lowest concentration which did not show any growth of the tested micro-organism after macroscopic evaluation was determined as the MIC.

Cytotoxic activity- Brine shrimp lethality bioassay: Brine shrimp lethality bioassay (Meyer B.N. et al., 1982) technique was applied for the determination of general toxic property of the leaf and fruit extracts of Averrhoa bilimbi. Here, in vivo lethality test has been carried out using brine shrimp nauplii eggs i.e. Artemia salina. Eggs were placed in one side of a small tank divided by a net containing $3.8 \% \mathrm{NaCl}$ solution for hatching. In the other side of the tank was placed a light source to attract the nauplii. After 2 days of hatching period the nauplii were ready for the experiment.

Four milligrams $(4 \mathrm{mg})$ of each sample was accurately measured and dissolved in DMSO to get varying concentrations $400,200,100,50,25$, $12.50,6.25,3.125,1.563$ and $0.781 \mu \mathrm{g} / \mathrm{ml}$. Forty five brine shrimp nauplii were then placed in each vial. For the control test of each vial, one vial containing the same volume of DMSO plus water up to $10 \mathrm{ml}$ was used.

Mortality was observed and recorded after 24 hour of incubation, using a magnifying glass and the number of survivors in each vial were counted and noted. From these data, the percentage of 
mortality of the nauplii was calculated for each concentration. Mortality was corrected using Abbott's formula (Abbott et al., 1925). The mortality data was subjected to Probit analysis according to Finney (1947) and Busvine (1971). The $\mathrm{LC}_{50}$ value with its $95 \%$ confidence limit was calculated according to F. Matsumura (1985).

\section{RESULT}

The consistent and reproducible results obtained using the disc diffusion techniques showed in Table-1 that the fruit extract exhibited more antibacterial potential than the leaf one, reflecting their qualitative and quantitative biochemical differences. The antibacterial activity was highest for the fruit extract against the Gram-negative Salmonella paratyphi $(23.0 \pm 0.50 \mathrm{~mm})$ and the Gram-positive Bacillus megaterium (19 \pm 0.40 $\mathrm{mm}$ ) bacteria, somewhat weaker against the Staphylococcus aureus, Bacillus subtilis, while with the leaf extract poor activity was observed against all 12 bacteria. Salmonella paratyphi was the most sensitive microorganism to the extracts examined in this study.

Table-1: Result of the antibacterial activity of methanolic extract of leaf and fruit part of Averrhoa bilimbi

\begin{tabular}{|c|c|c|c|}
\hline \multirow[b]{2}{*}{ Name of Bacteria } & \multicolumn{3}{|c|}{ Zone of Inhibition $(\mathrm{mm}) \pm \mathrm{SD}$} \\
\hline & 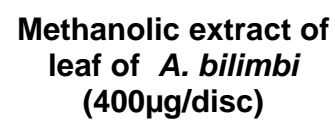 & 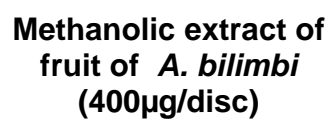 & Kanamycin $(30 \mu \mathrm{g} / \mathrm{disc})$ \\
\hline \multicolumn{4}{|l|}{ Gram positive } \\
\hline Staphylococcus aureus & $6.0 \pm 0.25$ & $18.0 \pm 0.20$ & $25.0 \pm 0.21$ \\
\hline Bacillus megaterium & $6.0 \pm 0.30$ & $19.0 \pm 0.40$ & $30.0 \pm 0.55$ \\
\hline Bacillus subtilis & $7.0 \pm 0.20$ & $18.0 \pm 0.21$ & $32.0 \pm 0.31$ \\
\hline Sarcina lutea & $6.0 \pm 0.31$ & $18.5 \pm 0.17$ & $28.0 \pm 0.35$ \\
\hline \multicolumn{4}{|l|}{ Gram negative } \\
\hline Salmonella paratyphi & $7.0 \pm 0.50$ & $23.0 \pm 0.50$ & $30.0 \pm 0.10$ \\
\hline Salmonella typhi & $6.0 \pm 0.45$ & $20.0 \pm 0.80$ & $33.0 \pm 0.20$ \\
\hline Escherichia coli & $6.5 \pm 0.15$ & $19.0 \pm 0.81$ & $32.0 \pm 0.80$ \\
\hline Shigella dysenteriae & $7.5 \pm 0.50$ & $20.0 \pm 0.60$ & $28.0 \pm 0.40$ \\
\hline Shigella boydii & $8.0 \pm 0.25$ & $19.0 \pm 0.20$ & $36.0 \pm 0.15$ \\
\hline Vibro parahemolyticus & $7.0 \pm 0.50$ & $20.0 \pm 0.35$ & $26.0 \pm 0.45$ \\
\hline Vibro mimicus & $8.0 \pm 0.44$ & $18.5 \pm 0.50$ & $30.0 \pm 0.20$ \\
\hline Pseudomonas aeruginosa & $6.5 \pm 0.44$ & $18.5 \pm 0.45$ & $30.0 \pm 0.06$ \\
\hline
\end{tabular}

The values are expressed as means of 3 repetitions \pm Standard Deviations (SD)

Tested at a concentration of $400 \mu \mathrm{g} / \mathrm{disc}$

Minimum inhibitory concentration (MIC) values of the fruit extract were $32 \mu \mathrm{g} / \mathrm{ml}$ against Shigella dysenteriae and $128 \mu \mathrm{g} / \mathrm{ml}$ against Vibro parahemolyticus, Salmonella paratyphi, Salmonella typhi, Shigella boydii, Sarcina lutea (Table-2). The Minimum inhibitory concentration
(MIC) value against Staphylococcus aureus was $256 \mu \mathrm{g} / \mathrm{ml}$. Only fruit portion was selected for MIC determination because it showed significant antibacterial activity compared to leaf and only those bacterial strains which showed greater zone of inhibition were selected for MIC test. 
Table-2: Minimum Inhibitory Concentration (MIC) of methanolic fruit extract of $A$. bilimbi

\begin{tabular}{|l|c|}
\hline \multicolumn{1}{|c|}{ Name of Bacteria } & $\begin{array}{c}\text { Methanolic extract of } \\
\text { fruit of A. bilimbi } \\
(\boldsymbol{\mu g} / \mathbf{m l})\end{array}$ \\
\hline Gram positive \\
\hline Staphylococcus aureus & 256 \\
\hline Sarcina lutea & 128 \\
\hline Gram negative & 128 \\
\hline Salmonella typhi & 32 \\
\hline Shigella dysenteriae & 128 \\
\hline Shigella boydii & 128 \\
\hline Vibro parahemolyticus &
\end{tabular}

From MIC values, it was found that the fruit extract was more potent against Salmonella paratyphi, Salmonella typhi, Shigella dysenteriae and Vibro parahemolyticus.

In case of brine shrimp lethality bioassay, the lethality of the methanolic extracts of the leaf and fruit of Averrhoa bilimbi were evaluated against Artemia salina. Figure-1 shows the results of the brine shrimp lethality testing after 24 hours of exposure to the samples and the positive control, Vincristine sulfate (VS). The $\mathrm{LC}_{50}$ were found to be $12.96,92.51$ and $3.05 \mu \mathrm{g} / \mathrm{ml}$ for fruit, leaf and Vincristine sulfate respectively (Table-3).

Table-3: $\mathrm{LC}_{50}$ data of test samples of leaf and fruit of $A$. bilimbi and Vincristine sulfate

\begin{tabular}{|c|c|c|c|c|}
\hline \multirow{2}{*}{ Samples } & Regression line & $L^{2} C_{50}(\mu \mathrm{g} / \mathrm{ml})$ & \multicolumn{2}{|c|}{$95 \%$ Confidence Limit } \\
\cline { 4 - 5 } & & & Upper limit & Lower limit \\
\hline $\begin{array}{c}\text { Methanolic extract } \\
\text { of leaf }\end{array}$ & $y=0.7215 x+3.5814$ & 92.51 & 307.13 & 27.84 \\
\hline $\begin{array}{c}\text { Methanolic extract } \\
\text { of fruit }\end{array}$ & $y=0.9848 x+3.9045$ & 12.96 & 38.88 & 4.32 \\
\hline Vincristine sulfate & $y=1.0843 x+4.1084$ & 3.05 & 8.75 & 1.06 \\
\hline
\end{tabular}

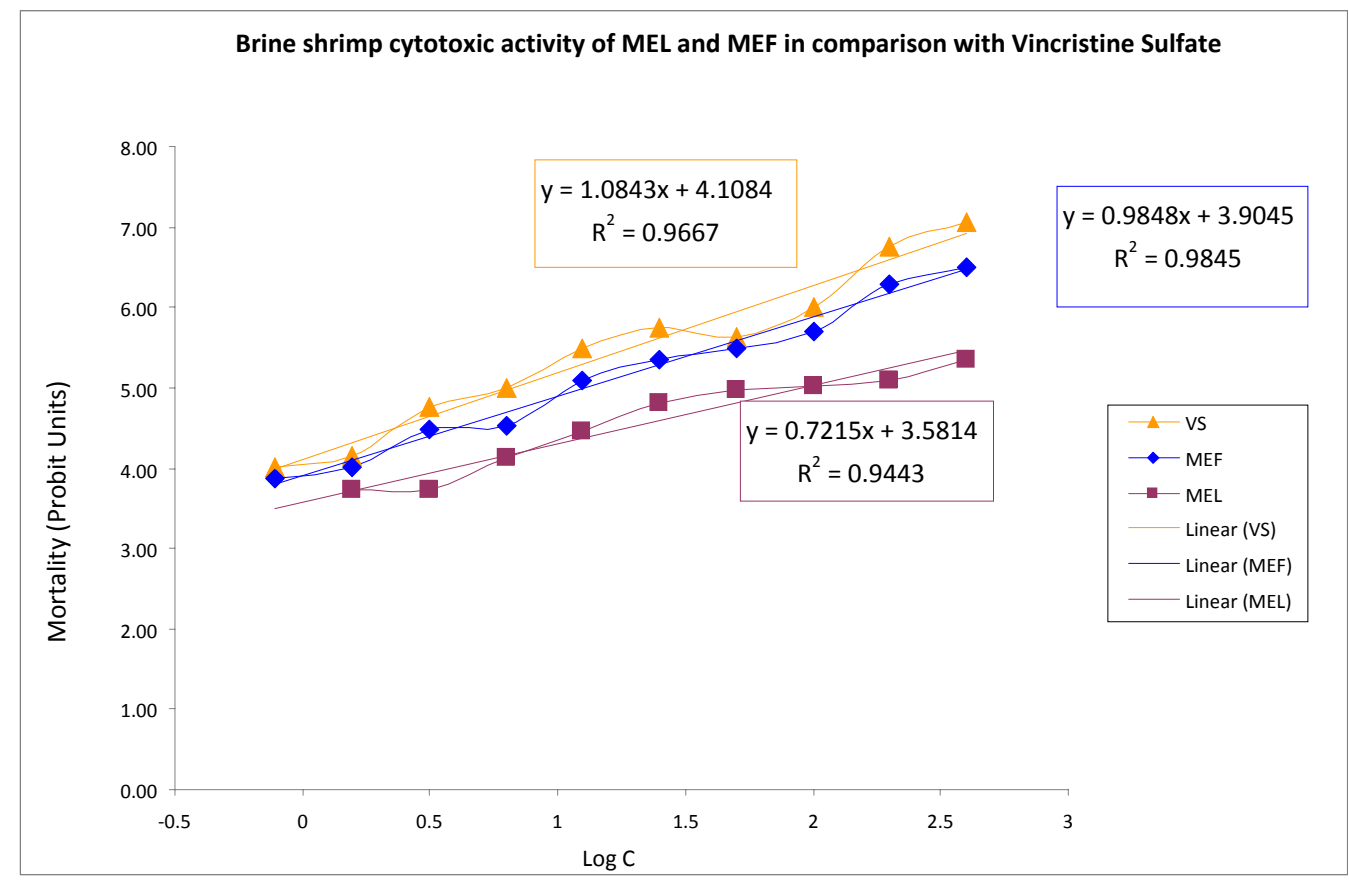

${ }^{*} \mathrm{MEL}=$ Methanolic Extract of Leaf, MEF = Methanolic Extract of Fruit, VS = Vincristine Sulfate.

Fig-1: Brine shrimp cytotoxic activity of methanolic extracts of fruit and leaf parts of the plant $A$. bilimbi in comparison with Vincristine Sulfate 


\section{DISCUSSION}

The ability of the fruit extract to exhibit antibacterial activity against some of the bacteria suggested the presence of hydrophilic and hydrophobic antibacterial compounds. It can be considered that the gram negative bacteria were more susceptible to the extracts when compared to the Gram-negative bacteria. Based on previous studies, the antibacterial activity of $A$. bilimbi could be associated with the presence of bioactive compounds of flavonoids type like luteolin and apigenin (Zakaria et al., 2007).

Previous study on the preliminary phytochemical screening on the fruit extract revealed the presence of flavonoids, saponins and triterpenoids but no alkaloids. It was also revealed that the methanol fruit extract was active on Escherichia coli, Klebsiella pneumoniae, Staphylococcus aureus, and Bacillus subtilis which were similar with our results (Nuru et al., 2009). The results of our antibacterial study revealed that the fruit extract showed a good inhibitory activity against the tested pathogens compared with the standard antibiotics which was kanamycin. In conclusion, the $A$. bilimbi fruits posses a potential antibacterial activity that requires further study.

In comparison with Vincristine sulfate, the cytotoxicity exhibited by the methanolic extracts of leaf and fruit of $A$. bilimbi were highly significant. $A$ comparison of cytotoxic activity of methanolic extracts of fruit and leaf with that of Vincristine sulfate has been shown in Figure-1. Fruit fraction was more cytotoxic than leaf portion. This clearly indicates the presence of potent bioactive principles in these extracts, which might be very useful as antiproliferative, antitumor, pesticidal and other bioactive agents.

Based on the data obtained, further studies involving isolation and identification of bioactive compounds from $A$. bilimbi extracts and antibacterial, cytotoxic studies using these isolated constituent should be carried out as it will help us in facing the emergence and spread of antibacterial resistance.

\section{CONCLUSION}

In conclusion, the $A$. bilimbi methanolic fruit extract has antibacterial activity against some bacteria and also has potent cytotoxic activity that require further studies, possibly to the extent of isolating and identifying the responsible compounds.

\section{REFERENCES}

Abbot W S 1925, A method of computing the effectiveness of an insecticide. J. Econ. Entomol. 18: 265-267.

Bauer, A.W., Kirby, W.M.M., Sherries, J.C. and Tuck, M. 1966. Antibiotic susceptibility testing by a standardized disc diffusion method. J. Am. clin. Pathol. 45, 493-496.

Busvine, J. R. 1971. A critical Review of the techniques of Testing Insecticides. Commonwealth Agriculture Bureau, London, pp.345.

Clardy J, Walsh C. 2004. Lessons from natural molecules. Nature 432:829-837.

F. Matsumura. 1985. Toxicology of Insecticides, 2nd Ed., Plenum, pp.14-16.

Finney, D.J. 1947. Probit analysis. Cambridge University press, London, pp. 333.

Jais, A.M.M., E.F.P. Henie, E.N.H.E. Zainuddin, H. Zaiton and Z.A. Zakaria, 2007. In vitro antibacterial activity of Averrhoa bilimbi L. leaf and fruits extracts. Int. J. Trop. Med., 2: 96100.

L. Silver and K. Bostian, 1990 Screening of natural products for antimicrobial agents, European Journal of Clinical Microbiology \& Infectious Diseases, Volume 9, Number 7, 455-461.

Meyer, B.N., Ferrigni N.R., Putnam J.E., Jacobsen J.B., Nicholsand D.E. and Mclaughlin, J.L. (1982). Brine shrimp; a convenient general bioassay for active plant constituents. Planta. Med. 45, 31-34.

Mitscher LA, Drake S, Gollapudi SR, 1987. A modern look at folkloric use of anti-infective agents. J Nat Prod 50: 1025-040.

Nurul Huda Bt. Abdul Wahab, Mohd Effendy Bin Abd Wahid, Mariam Bt. Taib, Wan Zuraida Bt.Wan Mohd Zain and Sarah Aqilah Bt. Anwar. Phytochemical screening and antimicrobial efficacy of extracts from Averrhoa bilimbi (Oxalidaceace) fruits against human pathogenic bacteria. Phcog.Net. Volume :1, Issue :1, June, 2009, Page No: 6466.

Orwa C, Mutua A, Kindt R , Jamnadass R, Simons A. 2009. Agroforestree Database:a tree reference and selection guide version 4.0. 
Am. J. Sci. Ind. Res., 2011, 2(4): 531-536

Selvin, J. and A.P. Lipton, 2004. Biopotentials of Ulva fasciata and Hypnea musiformis collected from the peninsular coast of India. J. Marine Science and Technol., 12: 1-6.

Rahman, M.S. and M.A.Rashid, 2008. Antimicrobial activity and cytotoxicity of Eclipta prostrata. Oriental Pharm. Exp. Med. 8, 47-52.

Reiner R., 1982. Antibiotics: An Introduction. F Hoffmamm-La Roche and Co. Ltd.Switzerland, pp: 21-27.
Verpoorte R, Choi YH, Kim HK., 2005. Ethanopharmacology and system biology: a perfect holistic match. J Ethnopharmacol 100: 53-56.

Z.A. Zakaria, H. Zaiton, E.F.P Henie, A.M Mat Jais and E.N.H. Engku Zainuddin, 2007. In vitro Antibacterial Activity of Averrhoa bilimbi L. Leaf and Fruits Extracts, Int. J. Trop. Med., 2(3): 96-100. 